\title{
Hydrogenated amorphous carbon as protective coating for a forming tool
}

\author{
J.F. Martinatti ${ }^{1}$, L.V. Santos ${ }^{2}$, N.C. Cruz ${ }^{1}$, and E.C. Rangel ${ }^{1, \text { a }}$ \\ ${ }^{1}$ Universidade Estadual Paulista (UNESP), Av. Três de Março, 511, Alto da Boa Vista, 18087-180 Sorocaba, SP, Brazil \\ ${ }^{2}$ Instituto de Pesquisas e Desenvolvimento (IP\&D), Universidade do Vale do Paraíba (Univap), Av. Shishima Hifumi, \\ 2911-São José Dos Campos, 12244-000, SP, Brazil
}

Received: 15 April 2011 / Received in final form: 14 July 2011 / Accepted: 5 August 2011 Published online: 28 October 2011 - (C) EDP Sciences 2011

\begin{abstract}
This paper investigates the performance of hydrogenated amorphous carbon $(a-\mathrm{C}: \mathrm{H})$ films as protective coatings for a forming tool made from AISI M2 steel coated with a titanium nitride (TiN) PVD commercial layer. The samples were initially cleaned in ultrasonic baths and subsequently in a plasma ablation procedure. Films were then deposited by plasma immersion ion implantation using $91 \%$ of acetylene and $9 \%$ of argon at a total pressure of $5.5 \mathrm{~Pa}$. Samples were biased with high voltage negative pulses, $P(T=3.33 \mathrm{~ms}$, pulse on-time: $0.03 \mathrm{~ms}$, pulse off-time: $3.30 \mathrm{~ms}$ and application rate: $299 \mathrm{~Hz})$ with amplitudes varying from 1.000 to $4.000 \mathrm{~V}$. The chemical structure and composition of the films were evaluated by infrared spectroscopy. The roughness was determined by profilometry while the surface topography and morphology were investigated by atomic force microscopy and scanning electron microscopy, respectively. The friction coefficient was determined by the ball on disk technique. A decrease in the proportion of $\mathrm{C}-\mathrm{H}$ and $\mathrm{O}-\mathrm{H}$ groups was observed while the concentration of dangling bonds enhanced with increasing $P$. Sharp structures were detected on the film surface affecting roughness in two different ways: it increased with enhancing pulse magnitude in the smoothest substrate (AISI M2) and decreased in the roughest one (AISI M2-TiN). The best tribological result was found for the sample deposited with $3.600 \mathrm{~V}$ of bias onto TiN-AISI M2 steel.
\end{abstract}

\section{Introduction}

Even though hydrogenated amorphous carbon is a material of great technological interest, elevated levels of internal stress [1] associated to poor adhesion to metallic surfaces [2] hinder several applications. Specific studies should be developed to adjust the stress level and to promote stronger connections to the particular substrate without deteriorating other properties. Plasma immersion ion implantation and deposition, PIIID [3], is a potential technique for improving the adhesion of $a-\mathrm{C}: \mathrm{H}$ films since it enables dilution of the substrate material with film constituents by $\mathrm{C}$ ion implantation. With adjusting the pulse characteristics and plasma intrinsic parameters, it is possible to control the energy of the implanted ions and then the characteristics of both film and substrate. In the presented work the suitability of $a-\mathrm{C}: \mathrm{H}$ films, prepared by PIIID, as protective coatings for deep drawing tools was investigated.

\section{Experimental}

Films investigated here were produced in a system detailed described elsewhere [4]. Glass pieces, AISI M2 steel,

\footnotetext{
a e-mail: elidiane@sorocaba.unesp.br
}

mirror-like polished stainless steel and AISI M2 steel containing a commercial TiN top layer were employed as substrates. After chemical baths in an ultrasonic cube, the substrates were placed in the bottom electrode of the reactor and submitted to a plasma ablation procedure [5]. Deposition plasmas were then generated from $91 \%$ of acetylene $\left(\mathrm{C}_{2} \mathrm{H}_{2}\right)$ and $9 \%$ of argon at a total pressure of 5.5 Pa. Plasma was excited by the application of radiofrequency power $(100 \mathrm{~W})$ to the upper electrode while pulsing the substrate holder with rectangular high voltage negative signals (pulse width: $3.33 \mathrm{~ms}$, pulse on-time: $0.03 \mathrm{~ms}$, pulse off-time: $3.30 \mathrm{~ms}$ and application rate: $299 \mathrm{~Hz}$ ). Pulse magnitude was changed from 1.000 to $4.000 \mathrm{~V}$ while deposition time was $840 \mathrm{~s}$.

The thickness of the layers was determined from a step delineated on the glass surface masking part of its surface with a Kapton tape during depositions. Measurements were conducted in three different points of the step using a Veeco Dektak 150 profile meter. Surface average roughness, $R a$, was evaluated from $50 \mu \mathrm{m}$ long scans with the aid of the profile meter. Three different points were tested in each sample. Infrared Reflectance-Absorbance Spectroscopy (IRRAS) was applied to investigate the chemical structure of the films deposited onto polished stainless steel. Sixty-four spectra were collected for each sample with $4 \mathrm{~cm}^{-1}$ of resolution in a Jasco FTIR 410 


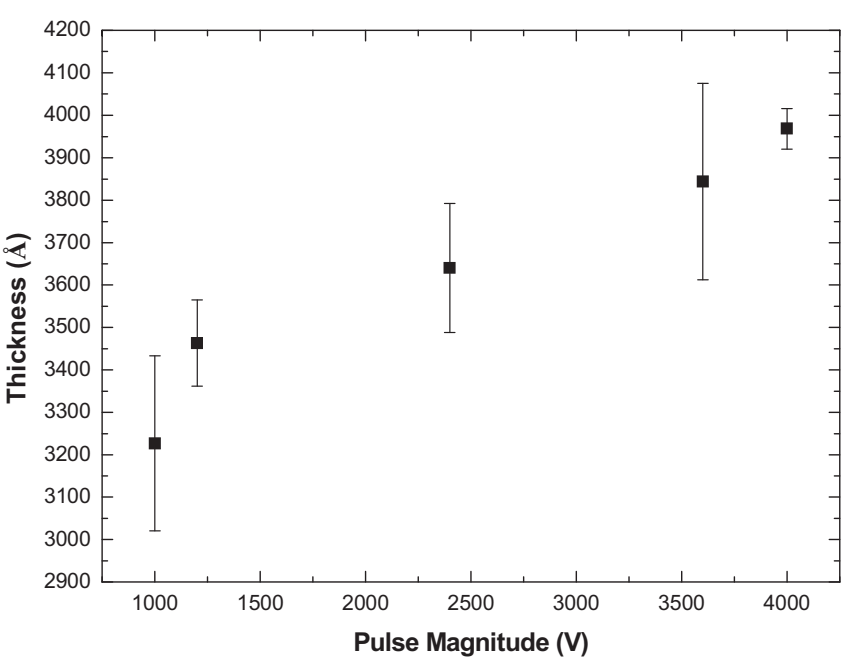

Fig. 1. Film thickness as a function of $P$.

device. Atomic force microscopy, AFM, images were generated employing the lateral force device of a nanoindenter Hysitron TriboIndenter. The loads applied to the Berkovich tip were 2.0 and $3.5 \mu \mathrm{N}$ while tip velocities were 10 and $100 \mu \mathrm{m} / \mathrm{s}$. Surface morphology was accessed by Scanning Electron Microscopy, SEM, using the secondary electrons detector of a Quanta Inspect S - FEI Company instrument. The beam energy was $20 \mathrm{kV}$. Dispersive Energy Spectroscopy, EDS, was employed to analyze the chemical composition of specific points of the samples through a detector connected to the scanning electron microscope. The friction coefficient was determined from ball on disk technique in an ultra micro tribometer CETR-UMT at $(20 \pm 1){ }^{\circ} \mathrm{C}$ and $50 \%$ of relative humidity. An AISI 404 steel sphere of $4 \mathrm{~mm}$ in diameter was applied in the linear reciprocal method at a constant force of $2 \mathrm{~N}$ and a velocity $10 \mathrm{~mm} / \mathrm{s}$. Inspection time was $300 \mathrm{~s}$. For the topography, AFM, SEM, EDS and tribology experiments, samples prepared onto bare M2 and TiN-M2 steel were employed.

\section{Results and discussion}

Figure 1 shows the thickness of the films, $h$, as a function of $P$. Thickness increases around $19 \%$ as $P$ is changed from 1.000 to $4.000 \mathrm{~V}$. The enhancement of the pulse magnitude affects the deposition rate of two different ways: it tends to decrease the deposition rate due to the intensification of the recoil implantation but it also increases plasma activity, accelerating the growing rate of the layer. Energy transferred from ions to neutral molecules in the plasma increases with increasing bias voltage. The dissociation degree and the rate of film growth rise as a consequence [6]. The enhancement of $h$ with $P$ reveals that the second effect is more important in the procedures employed here.

The mean roughness of the samples is presented in Figure 2 as a function of $P$ for AISI M2 and TiN-M2 steel before and after film deposition. For the roughest

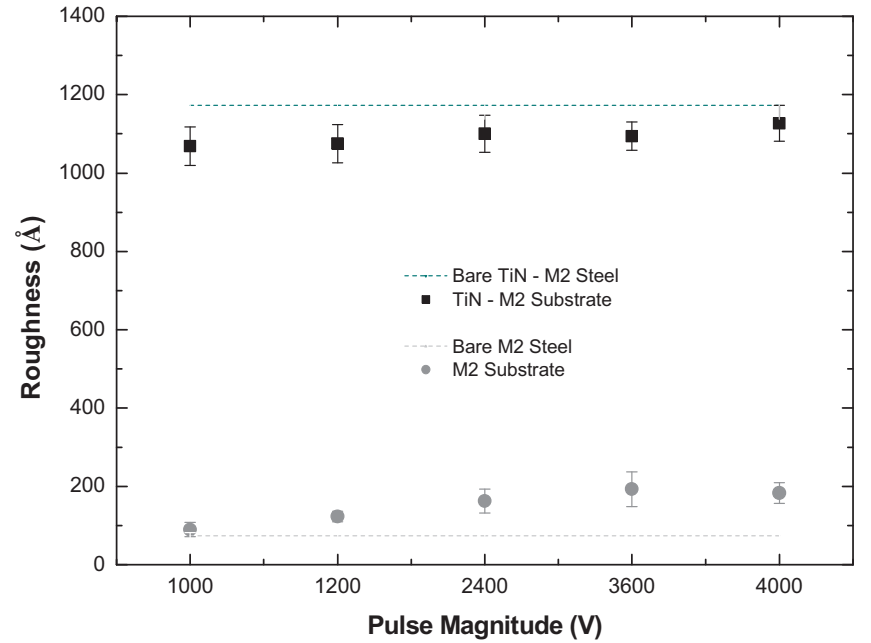

Fig. 2. (Color online) Roughness of the films as a function of $P$. Dotted lines represent the $R a$ values for the non-coated substrates.

TiN-M2 substrate all the films slightly decreased $R a$, indicating that film follows the substrate irregularities without hiding them. However, for the smoothest substrate (M2), film deposition tends to increase progressively $R a$ with increasing $P$, reaching around $200 \AA$ for $P=3.000 \mathrm{~V}$.

Figure 3 shows $50 \mu \mathrm{m}^{2}$ AFM images taken from samples prepared onto TiN-M2 system prior and after film deposition. The image of the bare substrate is composed by parallel grooves crossing all the scanned extension. Such patterns are created in the steel substrate, prior to the application of the TiN layer, by the hard turning process to adjust the piece dimensions to practical applications. This information explains the higher roughness values encountered for samples prepared onto TiN-M2 steel. But it is interesting to observe the change in the surface features after film deposition. The depth of the valleys is continuously decreased with increasing $P$, almost disappearing for the most intense deposition condition $(P=4.000 \mathrm{~V})$. Associated to this observation is the rise of sharp structures on the surface of the films, characteristic for plasma deposited amorphous carbon films.

The infrared spectra of the films are presented in Figure 4. Spectra of the films deposited with 1.000 and $1.200 \mathrm{~V}$ are characteristic of hydrogenated amorphous carbons deposited from acetylene and argon plasma mixtures [7]. Bands ascribed to $\mathrm{C}-\mathrm{H}$ vibrations are found around $2960\left(\nu\right.$ in $\left.\mathrm{CH}_{2}\right), 2870\left(\nu\right.$ in $\left.\mathrm{CH}_{3}\right), 1440(\delta$ in $\left.\mathrm{CH}_{3}\right)$ and $1370 \mathrm{~cm}^{-1}\left(\delta\right.$ in $\left.\mathrm{CH}_{3}\right)$ [8,9]. The incorporation of atmospheric oxygen in the structure is revealed by the absorptions related to $\mathrm{O}-\mathrm{H}\left(\nu 3400 \mathrm{~cm}^{-1}\right)$ and $\mathrm{C}=\mathrm{O}\left(\nu 1700 \mathrm{~cm}^{-1}\right)$ groups. Finally, the detection of a low intensity contribution around $1600 \mathrm{~cm}^{-1}$ is ascribed to stretching vibration of $\mathrm{C}=\mathrm{C}$ unit. Modifications are clearly detected in the spectra as pulse intensities higher than $1.200 \mathrm{~V}$ are applied. Although film thickness increases, the intensity of $\mathrm{C}-\mathrm{H}$ absorptions decreases with $P$, suggesting a reduction in the proportion of such groups upon higher energy bombardment. A continuous lowering in the intensity of the bands related to $\mathrm{O}-\mathrm{H}\left(3400 \mathrm{~cm}^{-1}\right)$ and 
J.F. Martinatti et al.: Hydrogenated amorphous carbon as protective coating for a forming tool

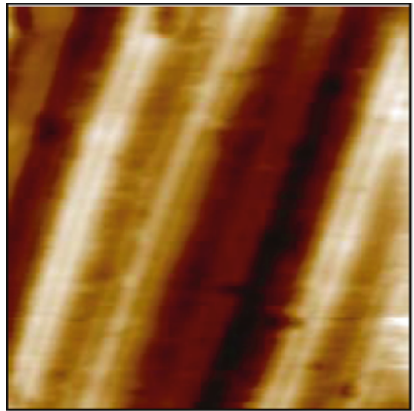

(a)

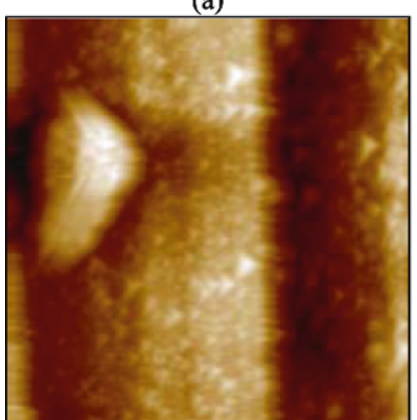

(c)

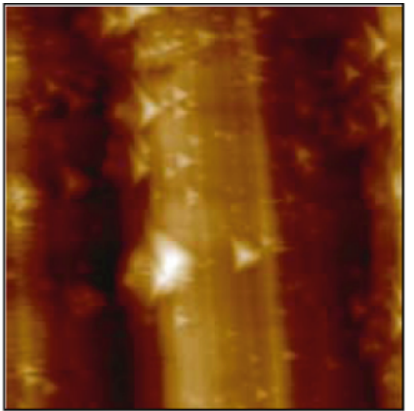

(b)

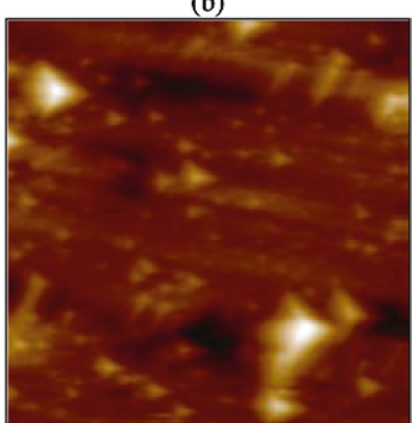

(d)

Fig. 3. (Color online) Atomic force microscopy images of the bare TiN-M2 substrate (a) and of the same material after exposure to plasma immersion ion implantation and deposition using polarization pulses of $2400 \mathrm{~V}$ (b), $3600 \mathrm{~V}$ (c) and $4000 \mathrm{~V}$ (d). Image area: $50 \mu \mathrm{m}$.

$\mathrm{C}=\mathrm{O}\left(1700 \mathrm{~cm}^{-1}\right)$ is also observed and interpreted as a result of the production of a low permeable and compact structure in which oxidative species cannot reach and saturate pendant bonds. This interpretation is confirmed by the rise of a peak around $870 \mathrm{~cm}^{-1}$ related to dangling bonds in C-H groups [10]. The intensity of such band is observed to rise with increasing $P$ consistently with the disappearance of oxygen-containing groups of the structure. It is also important to mention the rise of intense and wide contributions in the spectra of the films prepared with the higher $P$ values. This phenomenon was already observed in a previous work [11] and is related to optical interference of the infrared beam with the film.

The friction coefficient, $\mu$, of the samples prepared onto M2 steel is presented in Figure 5 as a function of the experiment time, $t$. Analyzing the behavior of the different curves in Figure 5, it is possible to notice that films prepared with the lowest and the highest pulse magnitude provided low protection to the surface, since $\mu$ assumes elevated values $(\sim 0.7)$ in the first moments of the test. However, the curves do not reach 0.8 , the friction coefficient for the bare M2 steel, revealing an improvement in the tribological properties of the pair. For the sample prepared with $3.600 \mathrm{~V}, \mu$ presented the slowest temporal growth, achieving the plateau established in the other samples after $100 \mathrm{~s}$ of the test. In the last $75 \mathrm{~s}$, however, the curve rises rapidly reaching around 0.8. The SEM images presented as insets in Figure 6 show the dimensions and aspects of the tracks formed in the different samples. Through these images and the EDS results (not shown

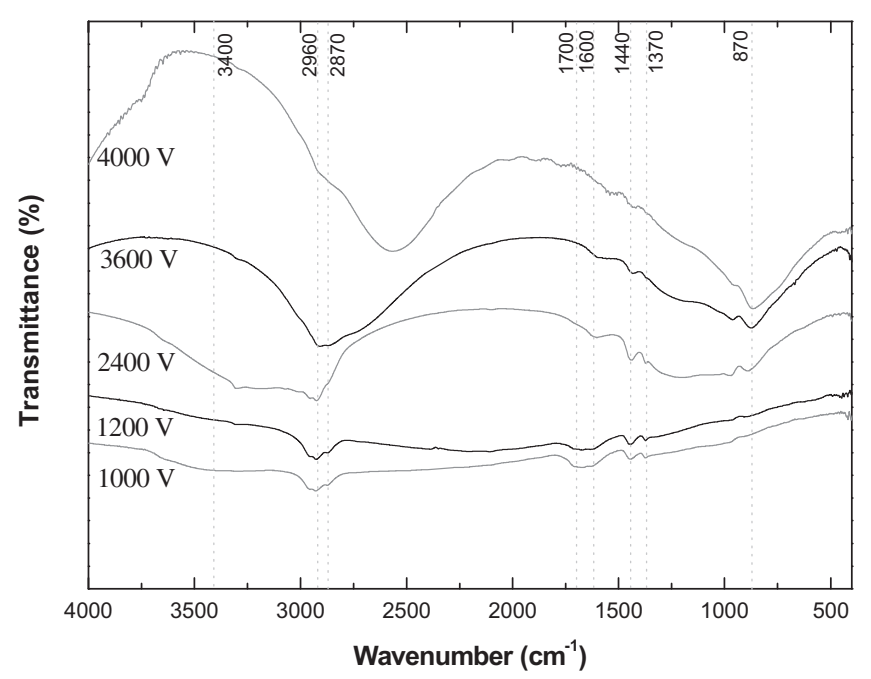

Fig. 4. Infrared spectra of films deposited by PIIID varying the magnitude of the polarization pulses. Spectra were acquired from films deposited onto polished stainless steel plates.

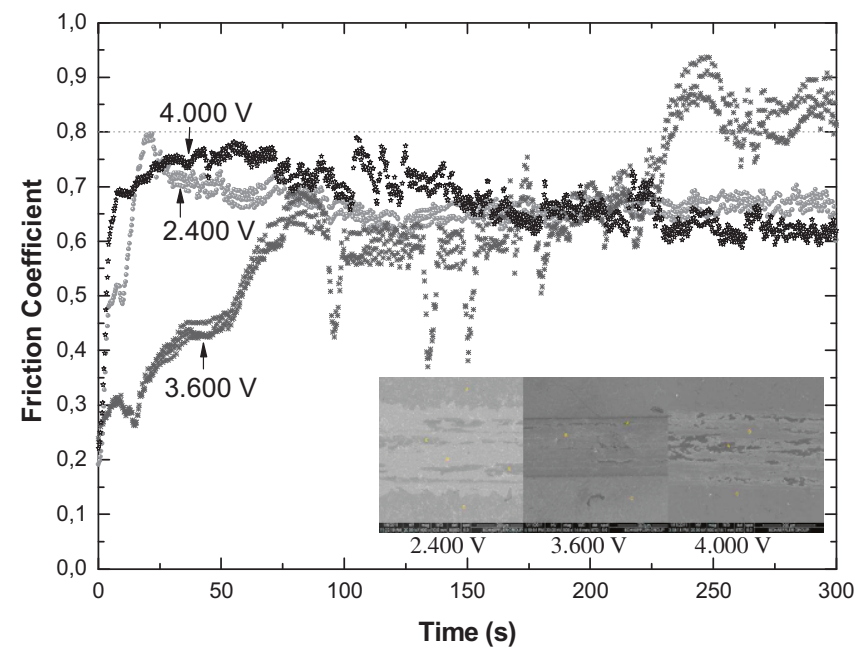

Fig. 5. (Color online) Friction coefficient as a function of $t$ for the pair AISI 404 steel sphere and samples prepared onto M2 steel with 2.400, 3.600 and $4.000 \mathrm{~V}$. Dashed line represents $\mu$ for the pair sphere-bare M2 steel. SEM microscopy images of the tracks formed during the friction measurements are presented as insets. The bar scale in the pictures is $200 \mu \mathrm{m}$.

here) it was found that samples prepared with 2.400 and $4.000 \mathrm{~V}$ presented higher amounts of the sphere material adhered to the surface and that, in the later, the film was totally removed even in regions away from the track. Furthermore, the preservation of the film prepared with $3.600 \mathrm{~V}$ on the substrate surface is evidenced.

Figure 6 shows the behavior of $\mu$ as a function of $t$ for samples deposited onto TiN-M2 substrate. The two fastest growth rates for $\mu$ were again observed in the samples prepared with 2.400 and $4.000 \mathrm{~V}$. What is interesting to notice, however, is that failure, identified as $\mu$ reaches around 0.6 , occurs after longer times than in the samples prepared directly onto M2 steel. A still better performance was attained for the sample prepared with $3.600 \mathrm{~V}$, in 


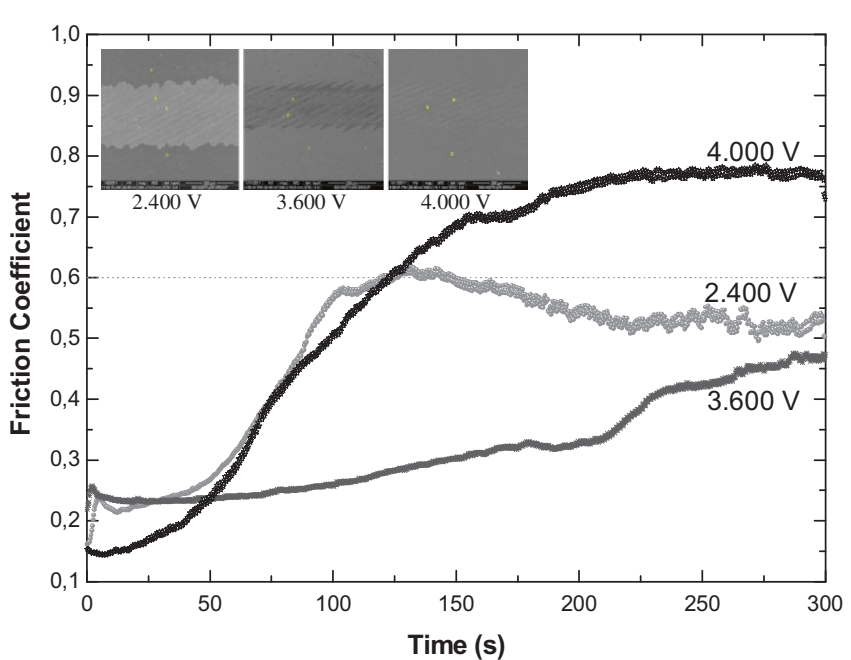

Fig. 6. (Color online) Friction coefficient as a function of $t$ for the pair AISI 404 steel sphere and samples prepared onto TiNM2 steel with 2.400, 3.600 and 4.000 V. Dotted line represents $\mu$ for the pair sphere-bare TiN-M2 steel. SEM microscopy images of the tracks formed during the friction measurements are presented as insets. The bar scale in the pictures is $200 \mu \mathrm{m}$.

which $\mu$ increases slightly with time and does not reach 0.6. The SEM images presented in this figure, associated to the EDS results (not presented), reveal adhesion of the tribometer sphere material on the surfaces prepared at 2.400 and $4.000 \mathrm{~V}$ but not on the material treated with $3.600 \mathrm{~V}$, which was indeed preserved on the substrate surface. Upon tribological tests, the film deposited with $4.000 \mathrm{~V}$ was completely removed from the whole observed region, and the track is then created directly in the TiN layer.

Despite the higher roughness, the better results obtained for substrates containing the TiN layer are ascribed to a stronger adhesion of the film to the substrate caused by $\mathrm{C}$ ion implantation in the first moments of deposition. This process is known to improve adhesion and to decrease the stress generated by compositional gradient [12]. As friction is directly related to connections on the surfaces, the lower concentration of dangling bonds produced in the film deposited with $3.600 \mathrm{~V}$ is pointed out as responsible for the best result encountered for such film in both substrates. For the most severe test condition (300 s), film deposited onto TiN-M2 steel enhanced the system performance in $25 \%$, which could represent a great cost reduction in a series of technological applications.

\section{Conclusions}

Hydrogenated amorphous carbons with thicknesses ranging from 0.30 to $0.40 \mu \mathrm{m}$ were deposited from acetylene and argon by PIIID. The proportion of hydrogen and oxygen in the structure was observed to depend on the pulse magnitude. Film surface is composed by sharp irregularities sparsely dispersed in a uniform matrix. The application of the film increased the roughness of the smoothest substrate but decreased the roughness of the most irregular one. Chemical composition and structure of the films were observed to be more decisive for friction than roughness. The best tribological result was encountered for the film containing the lowest concentration of pendant bonds. In this case, there was an association of low friction coefficient and good durability, even at the very severe tribological conditions imposed during the tests. Finally, the reduction of $25 \%$ in the friction coefficient may represent an enormous economy for a series of industrial areas.

The authors acknowledge the financial support of FAPESP (São Paulo State Research Foundation).

\section{References}

1. K.W. Chen, J.F. Lin, Thin Solid Films 517, 4916 (2009)

2. M. Stüber, S. Ulrich, H. Leiste, A. Kratzsch, H. Holleck, Surf. Coat. Technol. 116-119, 591 (1999)

3. J. Pelletier, A. Anders, IEEE Trans. Plasma Sci. 33, 1944 (2005)

4. R.C.C. Rangel, M.E.P. Souza, W.H. Schreiner, C.M.A. Freire, E.C. Rangel, N.C. Cruz, Surf. Coat. Technol. 204, 3022 (2010)

5. L.C. Oliveira, M.Sc. dissertation, Paulista State University, 2008

6. N. Inagaki, Plasma Surface Modification and Plasma Polymerization, 1st edn. (Technomic Pub. Co., Lancaster, 1996)

7. E.C. Rangel, N.C. Cruz, C.M. Lepienski, Nucl. Instr. Methods B 191, 704 (2002)

8. J.L. Andújar, M. Vives, C. Corbella, E. Bertran, Diam. Relat. Mater. 12, 101 (2003)

9. J. Robertson, Mater. Sci. Eng. R 37, 179 (2002)

10. http://www2.chemistry.msu.edu/faculty/reusch/ VirtTxtJml/Spectrpy/InfraRed/infrared.htm

11. E.C. Rangel, Ph.D. thesis, Campinas University, Brazil, 1999

12. P.W. Shum, Z.F. Zhou, K.Y. Li, C.Y. Chan, Thin Solid Films 458, 203 (2004) 